\title{
Monitoring dan Analisis Trafik di Jaringan USM Menggunakan Multi Router Traffic Grapher
}

\author{
Sri Handayani \\ Fakultas Teknologi Informasi dan Komunikasi \\ Universitas Semarang \\ Semarang \\ sri@usm.ac.id
}

\author{
Prind Triajeng Pungkasanti \\ Fakultas Teknologi Informasi dan Komunikasi \\ Universitas Semarang \\ Semarang \\ prind3ajeng@yahoo.com
}

\begin{abstract}
Faculty of Information and Communication Technology (FTIK) USM is one of the faculty are experiencing rapid development both of the number of students and the amount of infrastructure. FTIK occupying the building $M$ and $Q$ as lectures and laboratory building for student. FTIK is growth oriented faculty of Information Technology, of the entire student FTIK and academic staff need internet access to support existing teaching and learning process. When the researchers were in building $M$ and $Q$, Our will compete for free internet access is provided USM because the bandwidth is allocated evenly to rent USM. The fact that there are today, when researchers were on the 2nd floor of building A, as home base for the Faculty of Agricultural Technology, researchers gain access internet very easily. This is contrary to the conditions in the building $M$ and $Q$, whereas the number of students in the Faculty of Agricultural Technology, not as much as in FTIK.

Based on the above problems, reserchers are interested to observe, analyze the access bandwidth at USM that occured during the period of active classes and the end of the course by means of internet access at USM monitoring using NDLC (Network Development Life Cycle) and will appear in the display MRTG.

Objectives to be achieved by theresearcher is output obtained from a study that is able to provide inout to the wisdom of allocating bandwidth has been hired can be used optimally by the entire academic community USM.
\end{abstract}

\section{Keywords - Bandwidth USM, NDLC, MRTG}

\section{PENDAHULUAN}

Saat ini lebih dari 12.000 mahasiswa menuntut ilmu di Universitas Semarang (USM), aktifitas belajar mengajar di USM untuk perkuliahan pagi dan sore sangat meningkat pesat. Peningkatan jumlah mahasiswa tentu harus seiring dengan peningkatan pelayanan dan infrastruktur yang ada.
Salah satu fakultas yang men mengalami perkembangan pesat baik dari jumlah mahasiswa dan jumlah infrastruktur adalah Fakultas Teknologi Informasi dan Komunikasi (FTIK). Di kampus USM, FTIK menempati gedung M, Q sebagai gedung perkuliahan dan laboratorium bagi mahasiswa FTIK. Sebagai fakultas yang berorientasi pada perkembangan Teknologi Informasi, tentu seluruh mahasiswa FTIK dan staff akademik (dosen dan karyawan) di FTIK memerlukan akses internet untuk menunjang proses belajar mengajar yang ada. Saat peneliti berada di gedung $\mathrm{M}$ atau $\mathrm{Q}$, tak jarang peneliti dan mahasiswa akan memperebutkan akses internet gratis yang disediakan USM karena bandwidth yang disewa USM dialokasikan merata ke 8 gedung perkuliahan berlantai 3 yang dimiliki USM. Kenyataan yang ada saat ini, saat peneliti berada di gedung A lantai 2, sebagai home base untuk Fakultas Teknologi Pertanian, peneliti memperoleh akses internet yang sangat mudah. Ini sangat bertolak belakang dengan kondisi di gedung $\mathrm{M}$ dan $\mathrm{Q}$, padahal jumlah mahasiswa dan staff akademik di Fakultas Teknologi Pertanian, tidak sebanyak di FTIK. Begitu pula saat peneliti berada di Auditorium USM, peneliti memperoleh akses internet dengan sangat mudah.

Dari pengalaman peneliti yang mencoba mengakses internet di beberapa gedung yang di miliki USM, ternyata di gedung $\mathrm{M}$ dan $\mathrm{Q}$ sebagai home base FTIK, peneliti sering mengalami kesulitan untuk memperoleh akses internet. Hal yang samapun dialami oleh beberapa rekan dosen, dan sejumlah mahasiswa FTIK.

Berdasarkan permasalahan di atas, peneliti tertarik untuk mengamati, menganalisis pengaksesan bandwidth di USM yang terjadi pada saat masa perkuliahan aktif ataupun masa akhir perkuliahan dengan cara memonitoring pengaksesan internet di USM. Tujuan utama yang ingin dicapai oleh peneliti adalah adanya luaran yang diperoleh dari hasil penelitian yang mampu memberi masukan terhadap kebijaksanaan tentang besarnya pengalokasian bandwidth yang ada di USM sehingga bandwidth yang telah disewa dapat dimanfaatkan secara optimal oleh seluruh civitas akademika USM. 


\section{TINJAUAN PUSTAKA}

\subsection{OSI (Open System Interconnection)}

OSI diperkenalkan oleh International Standard Organization (ISO), dengan maksud supaya tiap komputer/terminal yang dihubungkan ke jaringan agar mampu berkomunikasi dengan komputer/terminal lain yang dihubungkan menggunakan jaringan yang sama maupun berbeda. Karena alasan inilah sifat dari OSI merupakan sistem yang terbuka (open system). OSI terdiri atas 7 lapisan (layer). yaitu :

\begin{tabular}{|l|l|}
\hline 1 & Application \\
\hline 2 & Presentation \\
\hline 3 & Session \\
\hline 4 & Transport \\
\hline 5 & Network \\
\hline 6 & Data Link \\
\hline 7 & Physical \\
\hline
\end{tabular}

\section{Gambar 2.1. Model OSI}

ISO menganggap pembagian model OSI menjadi 7 layer, dianggap yang paling tepat. Pembagian model OSI menjadi 7 layer ini bertujuan untuk:

a) Mengurangi kompleksitas.

b) 2. Sebagai standarisasi interface dari berbagai vendor yang ada.

c) Menfasilitasi perkembangan jarkom dari berbagaivendor.

d) Menjamin kekompatibelan teknologi.

e) Mengendalikan perkembangan jarkom (jaringan komputer).

f) Memberi kemudahan dalam menjelaskan dan mempelajari jarkom.

Lapis Application berfungsi sebagai interface antara user dan komputer. Lapis ini bertanggungjawab untuk mengidentifikasi ketersediaan patner untuk berkomunikasi, menentukan resources, dan melakukan proses sinkronisasi komunikasi.

Lapis Presentation berfungsi menyediakan sistem penyajian data ke lapis aplikasi. Lapis ini berfungsi menyediakan sistem pembentuk kode (format coding) dan menyediakan proses konversi antara format kode yang berbeda. Lapis Session bertanggung jawab terhadap proses pembentukan, pengelolaan, dan pemutusan sesi antar komputer yang berkomunikasi.

Lapis Session bertugas mengendalikan dialog antar device atau node di jaringan.

Lapis Transport bertanggung-jawab dalam proses pengemasan data di lapis atasnya, menyediakan mekanisme proses multiplexing pada lapis di atasnya, dan menetapkan hubungan antara host pengirim dan host penerima dalam bentuk virtual circuit, serta menjamin proses pengiriman data yang dapat diandalkan.

Lapis Network bertanggung jawab mengarahkan perjalanan paket data (Routing) melalui jaringan, dan bertanggung-jawab mengelola sistem pengalamatan jaringan. Lapis Data Link menjamin bahwa pesan yang dikirim tepat sampai tujuan.

Lapis Physical adalah lapis yang mendeskripsikan kebutuhan fisik dari komunikasi antar komputer, baik kebutuhan electrical, dan mechanical.

\subsection{Protokol Jaringan}

Protokol merupakan aturan yang harus dimengerti oleh perangkat-perangkat yang akan berkomunikasi. Protokol memungkinkan data dikirim dan diterima bagian per bagian agar diperoleh transmisi yang handal, kemudian data tersebut disusun kembali sesuai data aslinya begitu sampai di tujuan. Proses penyusunan kembali urutan data di tujuan ini dinamakan reassembly.

Ketika data hendak ditransmisikan, protokol bertanggung jawab menjaga keutuhan komunikasi antar perangkat pengirim dan perangkat penerima dengan cara : memeriksa bila terjadi error, mengenali jenis gangguan, memberikan petunjuk bagi pengirim/penerima untuk mengenali pesan akhir yang telah dikirim/diterima.

\subsubsection{Protokol SNMP}

Simple Network Management Protocol (SNMP) adalah Internet Protocol Suite, yang dibuat oleh Internet Engineering Task Force (IETF) pada tahun 1988. Tujuan awal diciptakannya protokol SNMP dalah mengatur berbagai device yang semakin banyak seiring dengan berkembangnya jaringan internet. SNMP dikembangkan untuk menyediakan peralatan manajemen jaringan yang mendasar dan mudah diimplementasikan untuk rangkaian protokol TCP/IP (Transmission Control Protocol/Internet Protocol). SNPM merupakan protokol dari lapis Application yang digunakan untuk Network Management System, 
memonitor perangkat jaringan sehingga lebih mudah dalam memberi informasi bagi pengelola jaringan.

Server manajemen SNMP dapat melakukan test untuk memeriksa status antar perangkat jaringan yang terhubung secara fisik. Pada lapis Data Link, server manajemen SNMP digunakan untuk mengkonfigurasi, menaktifkan, dan mematikan koneksi di jaringan. Server manajemen SNMP dapat menerima frame data keluar dan masuk jaringan, dan mengetahui error pada setiap perangkat yang sedang berkomunikasi. Pada lapis Network, server manajemen SNMP memeriksa IP address assigments, address translation tables, dan routing tables. Di lapis Transport, server manajemen SNMP dapat menghitung durasi koneksi perangkat dengan TCP, sehingga server manajemen SNMP mampu menghitung trafik TCP dan UDP (User Datagram Protocol) serta menghitung error yang terjadi. Dengan demikian SNMP dapat digunakan untuk pengawasan, pengkoleksian statistik, pemeriksa unjuk kerja dan keamanan dari suatu jaringan. Untuk melakukan fungsi-fungsi tersebut SNMP dibagi menjadi tiga bagian yang saling berkerja sama satu dengan lainnya yaitu : Managed Device, Agent, dan Network Management System.

\subsection{MTRG}

Multi Router Traffic Grapher adalah tool yang biasa digunakan untuk memonitor beban trafik (traffic load) dalam suatu jaringan pada kurun waktu tertentu dalam bentuk tampilan grafis. Software yang dibuat oleh Tobias Oetiker dan Dave Rand ini menggunakan protokol SNMP (Simple Network Management Protocol) yang biasa dimiliki perangkat jaringan (seperti hub, switch, router, network interface card, access point, dsb). Hanya perangkat - perangkat yang mensupport SNMP yang dapat dipantau dengan MRTG.

Fungsi MRTG melakukan monitoring berdasarkan parameter SNMP yang dikembalikan oleh perangkat jaringan yang dimonitor oleh MRTG. MRTG akan melakukan query mengenai status trafik di suatu node jaringan Selanjutnya, MRTG akan menampilkan status trafik dalam bentuk grafik dari suatu halaman web tertentu.

Keunggulan dari MRTG adalah faktor kesederhanaan dan fungsionalitasnya. MRTG dapat dikonfigurasi dengan mudah untuk memantau penggunaan badwitdh dalam suatu perangkat yang mendukung SNMP, yang dapat memantau trafik dalam jangka waktu yang diinginkan user. Lonjakan penggunaan trafik menandakan adanya yang tidak beres di jaringan, pesan warning ini bisa dikirim via $e$ mail. Tampilan grafis dengan format HTML yang menunjukan adanya ntegrasi dengan web server memudahkan admin jaringan memantau jaringan kapanpun, dan dimanapun tanpa melalui proses authentifikasi.

\section{TUJUAN DAN MANFAAT PENELITIAN}

\subsection{Tujuan Penelitian}

Adapun Tujuan dari penelitian dengan judul : Monitoring dan Analisis Traffik di jaringan USM menggunakan Multi Router Traffic Grapher (MRTG), menghasilkan data dan informasi tentang keoptimalan penggunaan badwitdh di USM berdasarkan pengalokasian yang dilakukan secara merata.

\subsection{Manfaat Penelitian Bagi Peneliti}

1. Menambah pengalaman, pengetahuan, dan wawasan dalam melakukan penelitian.

2. Menambah pengalaman dan pengetahuan tentang jaringan.

3. Memahami kesederhanaan dan fungsionalitas yang telah diperoleh dari monitoring dan analisis trafik jaringan dengan menggunakan MRTG.

\subsection{Manfaat Bagi FTIK-USM Semarang}

1. Menumbuhkan semangat meneliti dan memotivasi rekan-rekan dosen di USM khususnya dosen-dosen di FTIK-USM Semarang.

2. Menjadi bahan masukan yang dihasilkan dari luaran suatu penelitian tentang kebijakan pengalokasian bandwidth di masa mendatang.

\subsection{Manfaat Bagi Mahasiswa}

1. Menjadi sumber inspirasi bagi mahasiswa untuk tertarik melakukan riset tentang jaringan, karena tema jaringan masih belum terlalu banyak diminati oleh mahasiswa yang sedang ataupun sudah melaksanakan Tugas Akhir.

2. Menjadi sumber inspirasi bagi mahasiswa untuk tertarik melakukan riset dengan objek yang dapat diambil dari sekitar kampus (USM). 


\section{METODOLOGI PENELITIAN}

\subsection{Jenis Data}

Jenis Data yang digunakan oleh peneliti ada dua jenis yaitu :

1. Data Primer, yaitu data-data yang diperoleh peneliti secara langsung, contohnya adalah pengalaman peneliti dari perbedaan kemudahan akses internet di beberapa gedung yang dimiliki USM

2. Data Sekunder, yaitu data-data yang diperoleh peneliti dari literatur, buku referensi, ataupun dari browsing internet.

\subsection{Metode Pengumpulan Data}

Metode pengumpulan data yang dilakukan dalam penelitian ini adalah :

1. Observasi: Mengamati kebutuhan akses internet dari user (pengguna) di USM.

2. Wawancara : Mengumpulkan informasi dari bagian Puskom USM, informasi yang peneliti terima adalah informasi dari Bp.Surono,S.Kom tentang besarnya bandwidth yang disewa USM dan pengalokasian bandwidth-nya yang disebar merata ke 8 gedung USM. Informasi dari Ibu Nora,S.T.,M.T dari pihak Astinet, Telkom

3. Studi Pustaka : Mengumpulan literatur, buku referensi ataupun dari browsing internet.

\subsection{Metode Pengembangan Sistem}

Metode pengembangan sistem yang digunakan dalam penelitian ini adalah NDLC (Network Development Life Cycle), yaitu suatu pendekatan proses dalam komunikasi data yang menggambarkan siklus yang tiada awal dan akhir dalam mengamati jaringan , mencakup tahap :

1. Analisis,menganalisis kebutuhan untuk melakukan penelitian, permasalahan yang ada, topologi jaringan di USM.

2. Desain, merancang jadwal monitoring jaringan dalam skala waktu tertentu.

3. Simulasi prototype,melakukan eksekusi penelitian (monitoring jaringan).

4. Implementasi ( Analisis dan perekaman hasil monitoring dengan di-capture)

5. Manajemen, pengelolaan alokasi bandwidth jaringan yang dilakukan administrator
Lokasi penelitian adalah jaringan leased line Universitas Semarang (USM).

\section{HASIL YANG DICAPAI}

Hasil monitoring dan analisis penggunaan bandwidth dengan MRTG dilakukan :

1. Per hari (Daily)

2. Per minggu (Week)

3. Per bulan (Month)

4. Masa kuliah aktif, masa akhir perkuliahan, dan masa libur perkuliahan.

\subsection{Hasil Monitoring dan Analisis MRTG}

Hari pertama monitoring (selama 1 minggu)

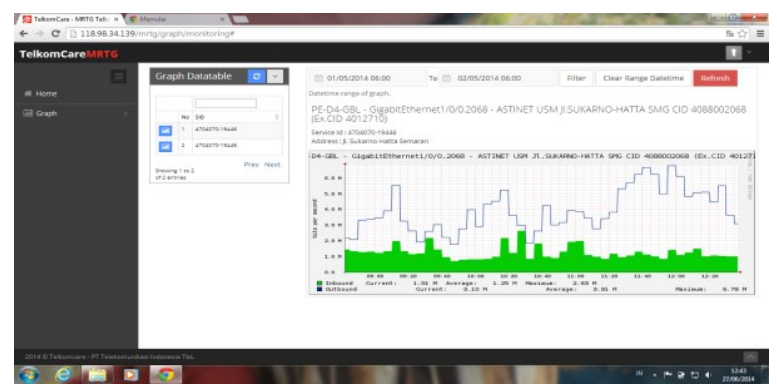

Gambar 5.1. MRTG Harian 1

Grafik berwarna hijau adalah Inbound (user melakukan proses upload). Sedang Grafik berwarna biru adalah Outbound (user melakukan proses download). Gambar 5.2 adalah hasil monitoring pengakses internet di USM pada tanggal 1 Mei 2014 jam 06.00 WIB s/d 2 Mei 2014 jam 06.00 WIB. Tampak pada gambar penggunaan bandwidth Outbound mencapai titik tertinggi dimana banyak user yang melakukan proses download pada Jum'at, 2 Mei 2014jam 11.55 - 12.00 WIB. Sementara penggunaan bandwidth untuk Inbound mencapai titik tertinggi dimana banyak user melakukan proses upload pada Jum'at 2 Mei 2014 jam 10.25-10.30 WIB.

\subsection{Lokasi Penelitian}


5.2. Monitoring minggu ke-1 ( Kamis 1-5-2014 jam 6.00 WIB - Kamis 8-5-2014 jam 6.00 WIB)

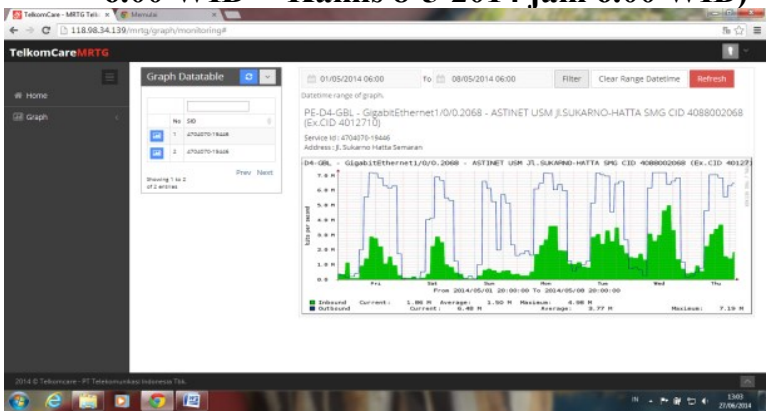

Gambar 5.2. MRTG Minggu ke-1

Pada gambar 5.2 tampak dari monitoring minggu 1, pemakaian bandwidth Outbound dan Inbound tertinggi dan terlama durasinya di hari Rabu, 7 Mei 2014. Pada hari Minggu, 4 Mei 2014 bandwidth yang ada tidak digunakan secara optimum baik untuk Outbound ataupun Inbound.

\subsection{Monitoring perbulan ( Kamis 1-5-2014 jam} 6.00 WIB - Minggu 1-6- 2014 jam 6.00WIB)

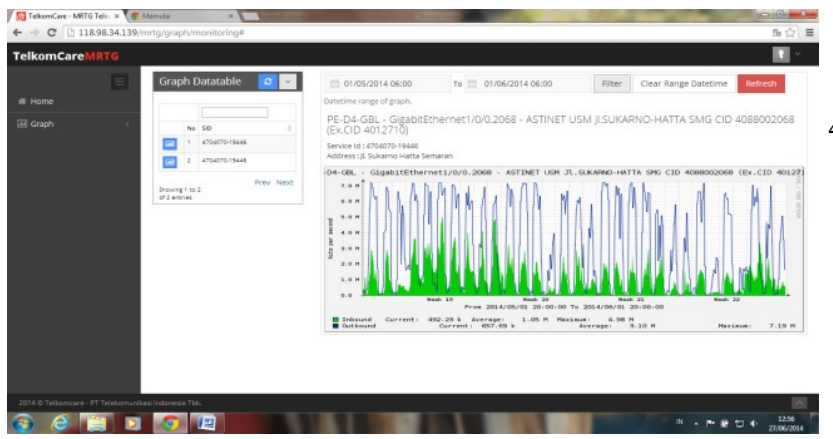

Gambar 5.3. MRTG bulanan

Pada Gambar 5.3 tampak dari monitoring bulanan, pemakaian bandwidth Outbound dan Inbound tertinggi terjadi di minggu ke 19 (bulan Mei 2014), pada saat itu perkuliahan masih berlangsung padat, mulai memasuki minggu awal bulan Juni 2014 minggu ke 23 ke atas pemakaian bandwidth Outbound ataupun Inbound mengalami penurunan, karena pada masa-masa ini, di USM telah mendekati masa akhir perkuliahan dan praktikum.

\section{KESIMPULAN DAN SARAN}

\subsection{Kesimpulan}

1. Alokasi bandwitdh yang merata ke seluruh gedung di USM membuat user harus memahami di lokasi gedung mana pengguna bandwitdhnya tidak optimum.

2. Gedung $\mathrm{M}$ dan $\mathrm{Q}$ merupakan gedung home base bagi Fakultas Teknologi Informasi dan Komunikasi (FTIK) USM, di kedua gedung ini selalu terjadi perebutan akses internet antar user (dosen, staf, mahasiswa), karena jumlah mahasiswa FTIK yang sangat banyak. Akibat dari perebutan akses internet ini, waktu akses internet bagi user yang telah mendapatkan IP terasa begitu lama (lemot)

3. Karena sifat MRTG yang sederhana, mudah dikonfigurasikan dengan perangkat jaringan yang mendukung SNMP, maka saat ini admin jaringan dipermudah untuk melakukan monitoring jaringan, karena ISP (Internet Service Provider) yang ada saat ini telah menyediakan data MRTG yang bisa diakses oleh admin jaringan ataupun peneliti. Adapun data MRTG yang peneliti dapatkan adalah dari situs : www.telkomcare.telkom.co.id/mrtg atau langsung menuliskan IP : 118.98.34.39

4. Data MRTG yang didapat oleh peneliti adalah data rekaman dari ISP, karena peneliti tidak pernah bisa mendapatkan data terkini dari MRTG. Data terbaru yang bisa diperoleh adalah data MRTG sehari sebelumnya, terlihat di Gambar 6.1 di bawah ini.

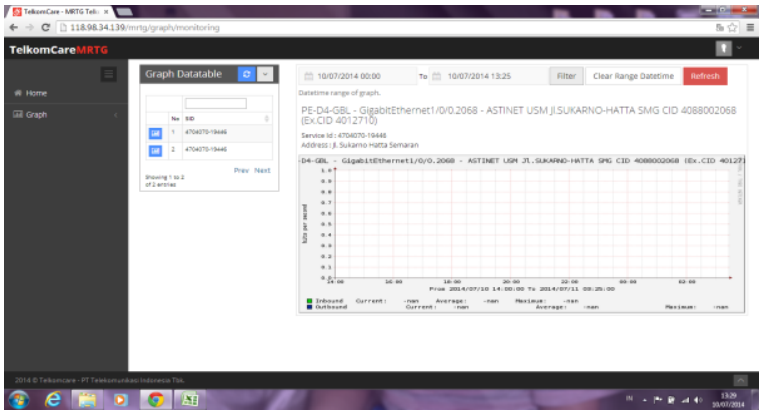

Gambar 6.1.MRTG up to date 


\subsection{Saran}

1. Kelebihan yang dimiliki MRTG dari segi kesederhanaan, yang mudah dikonfigurasikan dengan berbagai perangkat jaringan yang mendukung SNMP, ternyata juga memiliki kekurangan, karena ISP yang produknya disewa USM, dalam hal ini Astinet (Telkom) belum mampu memberikan data MRTG yang terkini/up to date. Data MRTG yang dapat diperoleh paling cepat adalah data MTG sehari sebelumnya.

2. Data MRTG yang diperoleh tidak mendukung proses perhitungan besaran trafik (volume trafik dan intensitas trafik). Besaran trafik adalah pengukuran trafik selama peralatan jaringan beroperasi, diukur berdasarkan waktu (kapan dan berapa lama).

3. Data MRTG yang diperoleh tidak mendukung proses perhitungan besaran trafik karena di tampilan MRTG-nya tidak memberikan informasi tentang : Total Inbound dan Total Outbound yang digunakan.

4. Penggunaan Bandwidth yang dialokasikan merata keseluruh gedung di USM, mengharuskan user pintar untuk mencari lokasi dimana bandwidth bisa diperoleh dengan sinyal yang baik.

5. Ke depannya diharapkan penelitian ini dapat menjadi masukan bagi pihak admin jaringan untuk melakukan manajemen jaringan dengan memikirkan pola alokasi bandwidth yang lebih baik lagi, dimana gedung yang paling sering menghabiskan alokasi bandwidth memperoleh alokasi bandwidth yang lebih besar, dibanding gedung yang jarang terjadi pemakaian bandwidthnya.

\section{Ucapan Terimakasih :}

1. Alhamdu lillahi rabbil'aalamiin, atas segala karunia dan hidayah dari Alloh SWT.

2. Ibunda tercinta, Hj.Entin Sumartini atas segala doanya.

3. Suamiku, Asriyono atas segala dukungan yang diberikan.

4. Anakku, Yondhika Farras Manshyur, yang selalu menjadi pelepas kejenuhan.

5. Struktural FTIK USM yang telah menfasilitasi penelitian ini.

6. LPPM USM yang telah menfasilitasi penelitian saya.

7. Rekan-rekan dosen di USM

8. Dan yang tak kalah pentingnya adalah DIKTI yang telah memberikan kesempatan kedua kalinya bagi saya untuk melaksanakan penelitian ini.

\section{DAFTAR PUSTAKA}

[1] Sofan, I., 2011, Jaringan Komputer, Penerbit Modula.

[2] Madcoms, 2010, Membangun Sistem Jaringan Wireless, Penerbit Andi.

[3] Rafiudin, R., 2009, Jaringan Komputer untuk Pemula, Elexmedia Komputindo.

[4] Purbo, O, W., Tanuhandaru, P., dkk, 2008, Jaringan Wireless di Dunia Berkembang, Penerbit Andi.

[5 ]www.chip.co.id diakses tanggal 10 November 2014 